\title{
Dinamika Ketenagakerjaan Di Indonesia: Penghapusan Sistem Outsourching (Kajian Undang-Undang Nomor 13 Tahun 2003 tentang Ketenagakerjaan)
}

\section{Manpower Dynamics in Indonesia:The Removal of Outsourcing System (A Study on Law Number 13 of 2003 about Manpower)}

\author{
Andy Arya Maulana Wijaya \\ Ilmu Pemerintahan Universitas Muhammadiyah Buton \\ bulawambona.87@gmail.com
}

\begin{abstract}
Abstrak
Penghapusan sistem outsourching menjadi tuntutan pekerja di Indonesia, disebabkan adanya ketimpangan dalam pelaksanaanya. Dimana sistem kerja outsorching ini sebenarnya telah diatur dalam UU No 13 Tahun 2003 tentang Ketenagakerjaan. Artikel ini kemudian akan menganalisis problematik tersebut, hal ini dapat dilihat pada tiga hal, yaitu hubungan kerja, Jaminan Sosial Tenaga Kerja dan Serikat Pekerja. Terjadi adanya penyimpangan dalam aturan yang dibuat, sehingga ada tuntutan penghapusan sistem outsourching oleh pekerja. Hubungan Kerja dalam sistem outsourching tidak jelas karena perjanjian hanya melibatkan pekerja outsourching dan perusahaan penyedia pekerja, namun tidak melibatkan perusahaan penyedia pekerjaan. Jaminan sosial tenaga kerja, merupakan salah satu bentuk perlindungan sosial bagi pekerja untuk mendapatkan hidup yang layak. Serikat Pekerja, dimana dalam prakterknya outsourching tidak jelasnya fungsi dan peran serikat pekerja dalam perusahaan.
\end{abstract}

Keywords: Ketenagakerjaan, Outsoursching\

\begin{abstract}
Indonesian workers demand the removal of outsourcing system, due to the gap in its implementation, in which this outsourcing working system has actually been governed in Law No.13 of 2003 about Manpower. This article then analyzed this problem; it could be seen from three points: job relation, Worker Social Security and Labor Union. There was a deviation from the rule developed, so that the workers called for the removal of outsourcing system. Job relation in outsourcing system was unclear because the agreement involved outsourcing workers and worker providing company only, but not job providing company. Worker social security was one of social protection form for the workers to get reasonable life. Labor Union had unclear function and role in the company in outsourcing practice.
\end{abstract}

\section{Keywords: Manpower, Outsourcing}

\section{A. Pendahuluan}

Pengaturan mengenai ketenagakerjaan di Indonesia masih seringkali menjadi problematik dalam dunia ketenagakerjaan. Persoalan kebijakan pemerintah yang selalu dituntut untuk kemudian dapat 
memberikan keadilan dan kesejahteraan para pekerja adalah persoalan utama.

Selain itu juga persoalan tenaga kerja Indonesia di beberapa negara juga semakin menambah catatan persoalan ketenagakerjaan di indonesia, upaya desentralisasi melalui otonomi daerah kemudian belum menjanjikan adanya usaha menciptakan kesejahteraan pekerja. Penentuan UMK yang masih ditemukan timpang dengan kondisi pekerja yang ada di beberapa daerah. Sejalan dengan itu kemudian, beberapa waktu lalu terjadi adanya peristiwa mogok buruh secara nasional di beberapa tempat di Indonesia. mereka kemudian menuntut adanya keadilan dan penghapusan sistem kerja outsorching. Dimana kondisi yang ada bahwa adanya hubungan kerja yang tidak jelas, ditambah UMK yang terkadang kecil, dengan adanya bagi hasil dalam mekanisme outsorching menjadikan kebutuhan hidup pekerja tidak bisa terpenuhi dengan maksimal dengan adanya tuntutan harga kebutuhan yang melonjak. Selain itu juga mengenai penanganan konflik industrial yang belum jelas diatur dalam UUK.

Demonstrasi yang disertai pemogokan ini kemudian ditanggapi dengan adanya ancaman bahwa kelompok pengusaha akan melakukan boikot produksi. Tentunya hal ini menjadi ancaman bagi kelangsungan ekonomi di Indonesia. memang pengaturan mengenai tenaga outsourching ini adalah legal di Indonesia, hal ini tercantum dalam
Undang-Undang nomor 13 Tahun 2003 mengenai ketenagakerjaan.

Pekerja outsourching menjadi salah satu permasalahan dalam dinamika ketenagakerjaan Indonesia, selain terkait dengan masalah kesejahteraan pekerja hal ini juga mampu menimbulkan adanya konflik komunal di masyarakat pekerja jika terus dibiarkan. Menurut Rekson Silaban (2009:48) mencatat beberapa masalah utama ketenagakerjaan yaitu masalah pengangguran dan berimplikasi pada meningkatnya jumlah pekerja sektor informal, masalah pendidikan dan komposisi, sistem pengupahan, praktek outsourching, masalah sistem pengawasan tenaga kerja, dan masalah jaminan sosial tenaga kerja.

Di samping itu juga berbagai pihak menilai sistem outsorching ini, tidak dapat memberikan keberdayaan dan kesejahteraan kepada pekerja atau buruh kita. Sehingga serangkaian protes mewarnai pelaksanaan sistem ini mulai dari mogok kerja hingga tuntutan di Mahkamah Konstitusi (MK) untuk mengadakan revisi terhadap UU No 13 Tahun 2003 tentang ketenagakerjaan (Pangaribuan, 2012).

Saat ini masalah pekerja outsourching menjadi salah satu pekerjaan dalam dinamika ketenaga kerjaan di Indonesia. sebenarnya dalam UUK sendiri mengatur batasan mengenai pengadaan pekerja outsourching ini kedalam pada bidang kegiatan yang tidak berhubungan langsung 
dengan proses produksi, antara lain: usaha pelayanan kebersihan (cleaning service), usaha penyediaan makanan bagi pekerja (catering), usaha tenaga pengaman (security), usaha jasa penunjang di pertambangan dan perminyakan, serta usaha penyediaan angkutan pekerja (transportation). Untuk itu dalam artikel ini akan mengemukakan pertanyaan mengenai dinamika ketenagakerjaan di Indonesia, kaitannya dengan tuntuntan penghapusan sistem outsoursching. Artikel ini akan menguraikan permasalahan yang mengemuka dalam pekerja outsourching ini, yaitu Hubungan Kerja, Kesejahteraan dan Hubungan Industrial dan penyelesaiannya menurut UUK no 13 tahun 2003.

\section{B. Tinjauan Pustaka}

\section{a. Hubungan Kerja di Indonesia}

Hubungan kerja dilihat pada berbagai model pekerjaan yang dilakukan antara pekerja dan perusahaan. Dimana di Indonesia hal ini diatur dalam UndangUndang No 13 tahun 2003 tentang Ketenagakerjaan hubungan kerja di Indonesia ada 3 bentuk, yaitu :

a. Hubungan Kerja Permanen, dalam istilahnya disebutkan Perjanjian Kerja Waktu Tidak Tertentu (PKWTT). Yang menurut Pasal 50 UU No. 13 Tahun 2003, hubungan kerja terjadi karena adanya perjanjian kerja antara pengusaha dan pekerja/buruh.

b. Hubungan kerja menurut jangka waktu tertentu (hubungan kerja kontrak). Hubungan ini dapat dilihat pada Pasal 57 ayat (2) yang menyatakan bahwa: perjanjian kerja untuk waktu tertentu (istilah UU adalah PKWT) yang dibuat tidak tertulis dinyatakan sebagai perjanjian kerja untuk waktu tidak tertentu. Hubungan ini dicirikan dengan perjanjian kerja yang tidak terlalu lama dan paling lama 3 tahun.

c. Hubungan kerja penempatan (outsource). Hubungan kerja ini dijelaskan pada pasal 65 dan 66 UUK. Pada hakekatnya Outsourcing adalah sebuah pola kerja dengan cara mendelegasikan operasi dan manajemen harian dari suatu proses bisnis/kerja pada pihak lain di luar perusahaan yang menjadi penyedia jasa outsourcing.

\section{b. Outsourching}

Sistem Outsourching merupakan wujud dari kebijakan pasar kerja fleksibel yang disyaratkan IMF dalam pemberian bantuan pemulihan krisis ekonomi di Indonesia. outsourching menjadi sah sejak keluarnya Undang-Undang Nomor 13 Tahun 2003 tentang Ketenagakerjaan (Wahyuni, 2011:212). Pada awalnya outsourching muncul sebagai akibat globalisasi ekonomi, persaingan usaha ketat, tuntutan pasar, fleksibilitas ekonomi dan efisiensi manajemen. Krisis ekonomi yang melanda dunia menuntut upaya pemulihan dengan dana yang besar. Keterbatasan dan mendorong pemerintah menarik investor asing maupun pinjaman luar negeri.

Salah satu isu yang ada adalah demokratisasi yang berimbas pada kebijakan ketenagakerjaan. IMF mengajukan dua solusi bagi Indonesia 
untuk mengatasi krisis, yaitu pertama dengan memberikan potongan pajak bagi dunia usaha, dan kedua menerapkan sistem pasar kerja yang fleksibel (Habibi, 2009: 7). Dengan model fleksibel ini kemudian dianalogikan bilamana permintaan berkurang, perusahaan dapat memberhentikan pekerja untuk mengurangi biaya produksi. Fleksibilitas ini bisa diwujudkan melalui sistem outsourching (Wahyuni, 2011: 216).

Rainey Jr (2005: 702) mengatakan Outsourcing bukanlah merupakan ide baru, ini diperkenalkan pada kepentingan organisasi dalam perampingan dan penghematan biaya dalam bisnis sejak tahun 1980 dan selanjutnya diterapkan juga pada pemerintah. Literatur tentang hal itu menjadi lebih rinci dan petunjuk spesifik, bahkan berkaitan dengan aplikasi pada sektor publik (Siegel, 2000), tetapi masih mengandung ambiguitas yang serius. Misalnya, Salah satu ketentuan yang diberikan dalam menggunakan outsourcing biasanya terkait adanya pengurangan biaya (Gelman dan Dell, 2002, Gay dan Essinger, 2000). Menurut Maurice Greaver, outsourching dipandang sebagai tindakan mengalihkan beberapa aktivitas perusahaan dan hal pengambilan keputusannya kepada pihak lain, dimana tindakan ini terikat dalam suatu kontrak kerjasama (dalam Yasar, 2008). Outsourcing juga diartikan sebagai pemindahan atau pendelegasian beberapa proses bisnis kepada suatu badan penyedia jasa, dimana badan penyedia jasa tersebut melakukan proses administrasi dan manajemen berdasarkan definisi serta kreteria yang telah disepakati oleh para pihak (Tunggal, 2009:308). Dalam penyediaan pekerja outsorching ini melibatkan pekerja/buruh outsorching, perusahaan penyedia pekerja dan perusahaan penyedian kerja.

Secara yuridis pelaksanaan Outsourcing (Alih Daya) dalam hukum ketenagakerjaan di Indonesia diartikan sebagai pemborongan pekerjaan dan penyediaan jasa tenaga kerja pengaturan hukum outsourcing (Alih Daya) di Indonesia diatur dalam Undang- Undang Ketenagakerjaan Nomor 13 tahun 2003 (pasal 64, 65 dan 66) dan Keputusan Menteri Tenaga Kerja dan Transmigrasi Republik Indonesia No.Kep.101/Men/VI/2004 Tahun 2004 tentang Tata Cara Perjanjian Perusahaan Penyedia Jasa Pekerja/Buruh dan Kepmenakertrans No. 220/Men/X/2004 tentang Syarat-syarat Penyerahan Sebagai Pelaksanaan Pekerjaan Kepada Perusahaan lain. Pengaturan tentang outsourcing ini sendiri masih dianggap pemerintah kurang lengkap. Outsourcing dalam regulasi ketenagakerjaan biasa hanya mencakup tenaga kerja pada proses pendukung (non core business unit) atau secara praktek semua lini kerja bisa dialihkan sebagai unit outsourcing (Tunggal, 2009: 334).

Intinya Outsorching adalah adanya pelimpahan kewenangan pada pihak ketiga untuk menyediakan pekerja untuk bidangbidang kerja tertentu, yaitu kegiatan yang tidak berhubungan langsung dengan proses 
produksi, antara lain: usaha pelayanan kebersihan (cleaning service), usaha penyediaan makanan bagi pekerja (catering), usaha tenaga pengaman (security), usaha jasa penunjang di pertambangan dan perminyakan, serta usaha penyediaan angkutan pekerja (transportation).

\section{Dinamika Ketenagakerjaan dalam Pekerja Outsourching}

Untuk lebih terarah dalam menganalisis apa yang kemudian dapat dilakukan dalam melihat isu penghapusan sistem outsorching ini ataupun upaya melakukan revisi terhadap UU No 13 Tahun 2003, maka perlu dilakukan pemetaan terhadap beberapa penyimpangan yang terjadi dalam pelaksanaan sistem outsorching dengan kaitannya terhadap keberadaan UU ketenagakerjaan tersebut. Dalam tulisan ini kemudian akan menjabarkan beberapa masalah yang ditimbulkan, melalui studi beberapa literatur terkait hal ini dan tentunya pemberitaan yang ada.

Adapun masalah yang timbul dari adanya sistem outsorching ini adalah :

1) Hubungan Kerja

Dalam UU No 13 Tahun 2003 tentang Ketenagakerjaan dikenal tiga model hubungan kerja yaitu hubungan kerja permanen, hubungan kerja menurut jangka waktu tertentu (kontrak) dan hubungan kerja penempatan (outsourching). dalam pembagian kerjanya, sistem outsorching hanya sebatas lima jenis pekerjaan yakni cleaning service, keamanan, transportasi, catering, dan jasa penunjang migas pertambangan.
Dalam pasal 56 ayat (1) UUK menyebutkan bahwa Perjanjian kerja dapat dibuat untuk waktu tertentu atau untuk waktu tidak tertentu. Membaca Pasal ini saja akan menimbulkan penafsiran bahwa ada kebebasan para pihak untuk membuat perjanjian kerja apakah berupa PKWTT atau PKWT, padahal sesungguhnya tidaklah demikian oleh karena dalam pasal-pasal berikutnya dapat ditemukan bahwa ternyata ada kondisi dan syarat yang ditentukan agar suatu hubungan kerja dapat dilakukan secara permanen maupun berjangka waktu (Agusmidah, 2007).

Dari hubungan kerja tersebut timbul suatu permasalahan hukum, karyawan outsourcing (Alih Daya) dalam penempatannya pada perusahaan pengguna outsourcing (Alih Daya) harus tunduk pada Peraturan Perusahaan (PP) atau Perjanjian Kerja Bersama (PKB) yang berlaku pada perusahaan pengguna oustourcing tersebut, sementara secara hukum tidak ada hubungan kerja antara keduanya (Wirawan, 2007. dalam Pikiran Rakyat.com)

Dalam teks UU no 13/2003 tersebut disebut dan dibedakan antara usaha atau kegiatan pokok dan kegiatan penunjang. Ada persamaan pokok antara bunyi UU tersebut dengan praktek industri, yaitu bahwa yang di outsource umumnya (tidak semuanya) adalah kegiatan penunjang (non core business), sedangkan kegiatan pokok (core business) pada umumnya (tidak semuanya) tetap dilakukan oleh perusahaan sendiri. Namun ada potensi 
masalah yang timbul. Potensi masalah yang timbul adalah apakah pembuat dan penegak undang-undang di satu pihak dan para pengusaha dan industriawan di lain pihak mempunyai pengertian dan interpretasi yang sama mengenai istilahistilah tersebut (R.Djokopranoto,2005; 5 dalam Wirawan 2007).

Setiap perusahaan kemudian harus menjelaskan terlebih dahulu apa yang menjadi pekerjaan utama dan pekerjaan penunjang kedalam suatu dokumen tertulis dan kemudian melaporkannya kepada instansi ketenagakerjaan setempat untuk mencegah terjadinya salah penafsiran mengenai kriteria core business (gofartobing.wordpress. com). Hubungan kerja yang fleksibel juga dapat membantu peningkatan dalam kinerja pekerja, sepeti pendapat Del Brio dkk.(2008) bahwa Dukungan fleksibilitas dalam kebijakan sumber daya manusia di tempat kerja, sebagai kebijakan umum dalam perusahaan, menyebabkan kinerja lingkungan yang lebih baik.

Namun dalam sistem outsourcing, hubungan kerja yang ada menjadi bias/kabur/tidak jelas, karena perjanjian kerja dibuat antara pekerja dengan perusahaan penyedia jasa pekerja. Padahal antara pekerja dengan Perusahaan Penyedia Jasa Pekerja tidak mengandung unsur pekerjaan, perintah dan upah, sehingga dapat dikatakan bahwa hubungan hukum antara pekerja dengan perusahaan penyedia jasa pekerja adalah hubungan hukum penempatan. Selanjutnya antara pekerja dengan perusahaan pengguna (user) secara otomatis terjadi hubungan kerja berdasarkan perjanjian kerja, karena disana ada unsur pekerjaan, upah, dan perintah (Agusmindah, 2007)

Maka dari itu dalam dengan adanya ketidakjelasan dalam memberikan hak-hak antara pekerja dan perusahaan penyedia kerja, pekerja/ buruh outsourching menginginkan adanya kejelasan dalam regulasi pemerintah. Untuk itu pekerja/buruh menuntut adanya revisi atau penghapusan sistem ini. Karena itu perlu adanya pengaturan yang jelas dalam undang-undang tentang hal ini.

\section{2) Jaminan Sosial Tenaga Kerja}

Jaminan sosial tenaga kerja diatur dalam dua peraturan perundangundangan. Pertama dalam UU No.3/1992 tentang Jamsostek mengenai hak pekerja atas jaminan sosial diatur dalam Pasal 3 ayat 2 yang berbunyi: Setiap tenaga kerja berhak atas jaminan sosial tenaga kerja. Disini digunakan term tenaga kerja, artinya tidak terlepas dari status pekerja tetap maupun pekerja outsourching dalam perlakuan mengenai jaminan sosial.

Namun kenyataanya bahwa outsourching kemudian mengurangi hak-hak pekerja, terutama terkait jaminan sosial tenaga kerja baik itu Jaminan Pemerliharaan Kesehatan (JPK), Jaminan Kecelakaan Kerja (JKK), Jaminan Hari Tua (JHT) maupun Jaminan Kematian (JK). Hal ini tidak akan diperoleh pekerja outsourching meskipun pekerja tersebut telah beberapa 
kali memperpanjang perjanjian kerjanya. Padahal dari sisi beban pekerjaan antara pekerja tetap dan pekerja outsourching adalah sama.

Di sisi lain, kesejahteraan yang bisa diterima pekerja/buruh outsorching dinilai masih rendah, saat ini Upah Minimum Karyawan (UMK) dalam bahasan untuk tahun 2013 Rp. 1.844 .000 angka ini masih dibawah angka 2 juta (tribunnews.com; 03/10/2012). Dan hal ini bisa jadi berbedabeda dalam kebijakan ditingkat provinsi. Padahal dalam sistem kerja outsorching, para pekerja/ buruh outsorching masih mendapat potongan dari perusahaan penyedia outsorching tersebut. Buruh hanya mendapatkan upah pokok sebesar upah minimum setempat tanpa tunjangan lain, sementara outsourced mendapat untung karena potongan pendapatan buruh (Arif Puyono; 2012). Padahal dalam Pasal 66 UU/30/2003 ayat c menyatakan, Penyediaan jasa pekerja atau buruh untuk kegiatan penunjang perusahaan harus memenuhi perlindungan usaha dan kesejahteraan, syarat-syarat kerja maupun perselisihan yang timbul menjadi tanggung jawab perusahaan penyedia jasa pekerja/buruh. Permasalahnya adalah karyawan memang bekerja di perusahaan pemberi pekerjaan namun ia tetap berstatus sebagai karyawan perusahaan penyedia pekerja. Untuk itu yang berkaitan dengan kesejahteraan pekerja/buruh merupakan tanggung jawab perusahaan penyedia jasa pekerja/buruh.
Pasal ini dinilai diskriminatif, dimana perusahaan penyedia pekerjaan seakan diberikan keleluasaan untuk "lepas tangan" mengenai pemenuhan kesejahteraan pekerja/buruh. Disamping itu juga perusahaan penyedia pekerjaan tidak bertanggungjawab terhadap tunjangan pensiun serta jaminan sosial para pekerja/buruh outsorching. Maka untuk itu, dalam tuntutan revisi UU 13/2003 pasal ini adalah salah satu yang diminta untuk dilakukan revisi. Adanya sistem kontrak dan outsourcing ini membuat posisi tawar pekerja atau buruh semakin lemah karena tidak ada kepastian kerja, kepastian upah, jaminan sosial, jaminan kesehatan, pesangon jika di PHK, dan tunjangan-tunjangan kesejahteraan lain.

Untuk itu desakan untuk pemerintah agar bertindak adil terhadap kaum buruh dengan melakukan pengawasan ketenagakerjaan yang ketat agar upah buruh tidak seenaknya saja dibayar murah oleh para pengusaha. Dan tentunya untuk segera merevisi UU Ketenagakerjaan dengan mengapus pasal sistem kerja kontrak agar kepastian kerja dan kesejahteraan bagi buruh dapat lebih terjamin.

\section{3) Serikat Pekerja}

Menurut Habibi (2009: 18-19) menyatakan dalam pandangan pancasila, pertumbuhan serikat pekerja yang terlalu kuat dalam hubungan industrial dianggap sebagi sesuatu yang negatif. Kondisi ini dapat menyebabkan timbulnya konflik terbuka antara pekerja dan pengusaha. Karena itu, 
serikat pekerja harus tumbuh secara proporsional. Namun Di dalam UU No.21/2000 tentang Serikat Pekerja/Serikat Buruh ditegaskan tentang hak pekerja/buruh untuk berserikat sebagaimana diatur dalam Pasal 5 yang berbunyi (1) Setiap pekerja/buruh berhak membentuk dan menjadi anggota serikat pekerja/serikat buruh, (2) Serikat pekerja/serikat buruh dibentuk oleh sekurang-kurangnya 10 (sepuluh) orang pekerja/buruh. Artinya bahwa walaupun pengaturannya secara proporsional namun keberadaa serikat buruh juga diperlukan sebagai wadah bagi aspirasi para pekerja di sebuah perusahaan.

Berdasarkan UU tersebut maka pada dasarnya pekerja baik yang berstatus permanen, PKWT dan outsourcing memiliki hak untuk berserikat. Persoalannya dalah bahwa karena kontrak pekerja outsourching yang bersifat tidak tetap dan bisa kapan saja berakhir. Maka keberadaan serikat pekerja hanya akan menghambat pekerjaan. Padahal dengan adanya serikat buruh kemudian bisa sebagai mediasi persoalan terhadap hakhak pekerja, misalnya jika ada masalah PHK, atau konflik antara pekerja dan perusahaan.

Sistem outsourching akan semakin melemahkan peran serikat pekerja dalam perusahaan karena hubungan kerja yang lebih bersifat individu antara perusahaan pengguna dengan tenaga kerja. Meskipun dalam UUK tidak disebutkan secara eksplisit bahwa pekerja tidak boleh berserikat, namun melemahnya posisi tawar pekerja akan membatasi upayanya memperjuangkan hak-haknya, terlebih ketika ancaman PHK oleh perusahaan semakin mudah dilakukan.

Dengan tidak adanya kesempatan dalam serikat pekerja ini kemudian, menjadikan masalah pekerja outsourching semakin banyak dalam posisinya sebagai dalam satu sumber daya manusia di dalam perusahaan yang juga memiliki hak-hak yang sama sebagai pekerja. Walaupun upaya memberikan perlindungan dengan diterbitkannya putusan Mahkamah Konstitusi (MK), pekerja alih daya berhak mendapat perlindungan kerja sesuai dengan Pasal 65 Ayat (4) dan Pasal 66 Ayat (2) UU Ketenagakerjaan.

Tetapi sejak adanya putusan MK tentang outsourcing masih banyak pemberi kerja atau perusahaan yang masih memberlakukan sistim Perjanjian Kerja Paruh Waktu (PKWT) yang banyak merugikan kaum pekerja/buruh, dimana masih banyak buruh yang bekerja dengan sistim outsourcing tidak mendapatkan fair benefits and welfare (Arif Puyono, 2012). Dan pekerja outsourching kemudian tidak mampu menyuarakan hak-hak mereka dalam serikat pekerja di perusahaan, sehingga ramai munculnya demonstrasi berbuntut pemboikotan pekerja beberapa waktu lalu.

Berdasarkan persoalan tersebut, maka masalah mengenai pekerja/buruh outsourching harus dicarikan jalan keluar 
yang efektif agar pekerja dapat lebih berdaya. Tuntutan terhadap revisi UU ketenagakerjaan dan penghapusan pelaksanaan sistem kontrak/ outsourching, menjadi agenda publik yang semestinya dicarikan jalan keluar yang baik. Sehingga kemudian sumber daya outsourching mendapatkan hak-hak yang sama dalam mekanisme ketenagakerjaan di Indonesia.

\section{Penutup}

Walaupun praktek outsourching legal dilakukan dalam perusahaan di Indonesia melalui UU No 13 tahun 2003 tentang ketenagakerjaa, serta pengaturannya dalam bidang apa saja dilakukan. Namun masih ditemukan beberapa kelemahan di dalam penerapan dilapangan, sehingga hal ini menunjukkan adanya inkonsistensi dalam penerapannya. Misalnya saja dalam hubungan kerja yang kemudian menjadi bias dan menyebabkan adanya ketidakjelasan hubungan antara pekerja dan perusahaan penyedia pekerjaan. Dalam penyediaan jaminan sosial juga masih ditemukan ketimpangan, yakni dengan tidak adanya perlindungan sosial terhadap pekerja. Kemudian hubungannya terhadap keberadaa serikat pekerja sebagai wadah aspirasi hak-hak pekerja, walaupun tidak ada larangan dalam pembentukannya namun regulasi yang ada tidak memberikan kesempatan untuk itu. ketiadaan serikat pekerja memungkinkan tidak adanya kesempatan pekerja untuk membela hak-haknya sebagai tenaga kerja, terlebih ketika menghadapi ancaman PHK dari perusahaan.
Permasalahan yang melingkupi pekerja dalam pelaksanaan outsourching ini meliputu hubungan kerja, jaminan sosial dan serikat pekerja. Perlu dicarikan jalan keluarnya yang efektif, dimana dapat memberikan keadilan terhadap hak pekerja outsourching sebagi tenaga kerja. Melakukan revisi terkait UU ketenagkerjaan sehingga lebih memperhatikan posisi pekerja perlu dilakukan, disamping itu pemerintah dan pemerintah pusat melakukan pengawasa intensif terhadap perjanjian outsourching yang dilakukan perusahaan pengguna pekerja outsourching. kemudian ditunjang dengan ketegasan pemerintah dalam menghadapi pelanggar undang-undang ketenagakerjaan, selain itu diperlukan juga adanya koordinasi regulasi pada setiap aturan mengenai hak-hak pekerja/buruh.

\section{Daftar Pustaka}

Agusmindah, Outsourching dan PKWT dalam Sistem Hubungan Kerja Merupakan Gejal Fleksibilitas Ketenagakerjaan, http://ocw.usu.ac.id/perburuhan/hk_ 628_slide_outsourcing_dan_PKWT_ dalam_sistem_hubungan_kerja_mer upakan_gejala_kebijakan_fleksibilita s_ketenagakerjaan.pdf, diakses pada 14 oktober 2012.

Arief Puyono, Inilah Alasan Logis Sistem Kerja Outsourcing Harus Dihapus, http://www.rmol.co/read/2012/10/03 /80287/Inilah-Alasan-Logis-SistemKerja-Outsourcing-Harus-Dihapus. di akses pada tanggal 14 oktober 2012 
Condrey, Stephen E (ed)., 2005. Handbook of Human Resource Management in Government, Second Edition. Jossey-Bass A Wiley Imprint, 989 Market Street: San Francisco.

Del Brio ,Jesus Angel., Beatriz Junquera, Monica Ordiz., Human Resources In Advanced Environmental Approaches - A Case Analysis, International Journal of Production Research, Vol. 46, No. 21, 1 November 2008, 6029-6053

Gofar Tobing, Outsourching di Indonesia, http://gofartobing.wordpress.com/20 10/02/01/outsourching-alih-dayadan-pengelolaan-tenaga-kerja-padaperusahaan-tinjauan-yuridisterhadap-undang-undang-nomor-13tahun-2003-tentang-

ketenagakerjaan/, diakses pada tanggal 14 oktober 2012

Habibi, Muhtar.,2009, Gemuruh Buruh di Tengah Pusaran Neoliberalisme: Pengadopsian Kebijakan Perburuhan Neoliberal Pasca Orde Baru. Yogyakarta; Gava Media.

Juanda Pangaribuan, Legalitas Outsourcing Pasca Putusan MK, http://www.hukumonline.com/berita/ baca/lt4f4b372fe9227/legalitasioutsourcing-i-pasca-putusan-mkbroleh--juanda-pangaribuan. diakses pada tanggan 14 oktober 2012.

Keputusan Menteri Tenaga Kerja dan Transmigrasi Republik Indonesia No.Kep.101/Men/VI/2004 Tahun 2004 tentang Tata Cara Perjanjian Perusahaan Penyedia Jasa Pekerja/Buruh
Kepmenakertrans No. 220/Men/X/2004 tentang Syarat-syarat Penyerahan Sebagai Pelaksanaan Pekerjaan Kepada Perusahaan lain

Mahyuni, Dinar., Posisi Pekerja Outsourching Dalam UndangUndang Nomor 13 Tahun 2003 Tentang Ketenagakerjaan. Jurnal Aspirasi Vol 2 No. 2, Desember 2011.

Rainey Jr ,Glenn W. 2005., Human Resource Consultants and Outsourcing: Focusing on Local Government (hal. 701-734).

Silaban, Rekson. 2009. Reposisi Gerakan Buruh, Peta Jalan Gerakan Buruh Indonesia Pasca Reformasi. Jakarta: Pustaka Sinar Harapan. Theresia Felisiani, Survei Disnakertrans, UMP 2013 Masih di Angka 1.844.000, http://www.tribunnews.com/2012/10 /03/survey-disnakertrans-ump-2013masih-di-angka-1.844.000. diakses oada tanggal 14 Oktober 2012.

Tunggal. Iman Sjahputra, 2009. PokokPokok Hukum Ketenagakerjaan, Harvarindo:Jakarta

Undang-Undang Nomor 13 Tahun 2003 tentang Ketenagakerjaan

Undang-Undang Nomor 21 Tahun 2000 tentang Serikat Pekerja/Serikat Buruh

Wirawan, Rubrik Hukum Teropong, Apa yang dimaksud dengan sistem outsourcing?, http://www.pikiranrakyat.com/cetak/0504/31/teropong/ komenhukum.htm. diakses pada tanggal 14 oktober 2012. 
Spirit Publik Volume 12, Nomor 2, Oktober 2017

Halaman 94-105 P-ISSN. 1907-0489 E-ISSN 2580-3875

Yasar, Iftida. 2008. Sukses Implementasi

Outsourching. Jakarta: PPM 
Spirit Publik Volume 12, Nomor 2, Oktober 2017

Halaman 94-105

P-ISSN. 1907-0489 E-ISSN 2580-3875 